\title{
O uso do paquímetro na motricidade orofacial: procedimentos de avaliação
}

\author{
Comentado por: Carla Cardoso ${ }^{1}$
}

Cattoni DM. O uso do paquímetro na motricidade orofacial: Procedimentos de avaliação. Barueri (SP): Pró-Fono; 2006.

Trata-se de um livro a respeito do uso do paquímetro na Fonoaudiologia, especialmente no trabalho com Motricidade Orofacial, contribuindo para a padronização de critérios diagnósticos das alterações do sistema estomatognático. A autora procurou adaptar os conhecimentos da Antropometria às necessidades da prática clínica do fonoaudiólogo, abrindo a possibilidade de registros mais objetivos do diagnóstico, dos procedimentos terapêuticos, prognóstico e resultados clínicos.

Tradicionalmente a avaliação fonoaudiológica das estruturas orofaciais baseia-se em procedimentos da antroposcopia, ou seja, a observação visual e a descrição subjetiva dos aspectos físicos.

O que esta obra propõe é que sejam utilizadas medidas minuciosas e objetivas dos mesmos aspectos observados. Trata-se de um procedimento que utiliza técnicas simples, que não envolvem riscos ou desconfortos para os pacientes pois não são invasivas - e têm baixo custo. Para evitar imprecisões nas medidas, é importante que elas sejam obtidas pelo mesmo profissional e que haja um cuidado rigoroso com a localização dos pontos faciais.

Segundo a autora, a antropometria pode ser usada, na Fonoaudiologia, com pacientes portadores de distúrbios da respiração, deglutição e mastigação, de alterações músculoesqueletais da face, de fissuras lábiopalatais e síndromes craniofaciais, de deformidades e disfunções craniofaciais adquiridas e de distúrbios neuromusculares.

A autora chama a atenção para o fato de que as medidas antropométricas não devem ser consideradas isoladamente, mas devem ser consideradas em conjunto com os dados obtidos no exame clínico.

Os instrumentos sugeridos para a tomada de medidas antropométricas objetivas são o paquímetro digital e a fita métrica de tecido, que possibilitam a obtenção de medidas em milímetros (mm).

O livro inclui uma descrição detalhada, ilustrada por fotos e esquemas, dos pontos antropométricos que determinam medidas clinicamente importantes, juntamente com a nomenclatura e abreviações padronizadas. As associações de dois desses pontos, que determinam as medidas de interesse, também estão ilustradas de forma simples e clara, permitindo ao fonoaudiólogo clínico a perspectiva objetiva dos procedimentos a serem executados.

Além de instruções sobre como obter as medidas orofaciais, a autora apresenta também sugestões sobre como calcular as proporções orofaciais, relacionando pelo menos duas medidas, e sobre quais são as proporções importantes para a clínica fonoaudiológica.

A descrição dos procedimentos de avaliação inclui o posicionamento do paciente, as orientações que devem ser transmitidas e os cuidados para a obtenção de medidas confiáveis.

São apresentados os parâmetros da literatura internacional sobre as medidas sugeridas e os resultados de uma pesquisa da autora com sujeitos normais entre sete e 11 anos de idade.

A publicação inclui um CD com o protocolo de coleta de dados para o registro objetivo e organizado das medidas obtidas.

Enfim, trata-se de uma publicação que pode contribuir muito para acrescentar objetividade à atuação fonoaudiológica, sem substituir a perspectiva clínica ou disputar espaço com ela. O livro constitui instrumento importante para o dia-a-dia do fonoaudiólogo, contribuindo para a construção de uma Fonoaudiologia baseada em evidências.

(1) Professora do Curso de Fonoaudiologia da Universidade do Estado da Bahia - UNEB - Salvador (BA), Brasil; Diretora do Curso de Fonoaudiologia das Faculdades Jorge Amado - Salvador (BA), Brasil.

Endereço para correspondência: Carla Cardoso. R. Cícero Simões, 191/ 1101, Pituba, Salvador - BA, CEP 41830-475. E-mail: cardoso.carla@uol.com.br 